\title{
Addressing financial toxicity in oncology care
}

\author{
Steven S. Coughlin ${ }^{1}$, Justin Xavier Moore ${ }^{1}$, Jorge E. Cortes ${ }^{2,3}$ \\ ${ }^{1}$ Department of Population Health Sciences, Medical College of Georgia, Augusta University, Augusta, GA, USA; ${ }^{2}$ Department of Medicine, Medical \\ College of Georgia, Augusta University, Augusta, GA, USA; ${ }^{3}$ Georgia Cancer Center, Augusta University, Augusta, GA, USA \\ Correspondence to: Professor Steven S. Coughlin, PhD. Department of Population Health Sciences, Augusta University, 1120 15 ${ }^{\text {th }}$ Street, AE-1042, \\ Augusta, GA 30912, USA. Email: scoughlin@augusta.edu.
}

Received: 18 May 2020; Accepted: 23 November 2020; Published: 25 September 2021.

doi: 10.21037/jhmhp-20-68

View this article at: http://dx.doi.org/10.21037/jhmhp-20-68

\section{Introduction}

There has been growing concern about the high costs of oncology care and associated financial distress and financial toxicity (1). Financial toxicity has been defined as the patient-level impact, objectively measured outof-pocket expenses, and self-reported emotional distress caused by the cost of oncology care $(2,3)$. More broadly, it is the deleterious effects of the financial stress caused by the diagnosis of cancer on the well-being of patients and their families (4). About $13 \%$ of non-elderly cancer patients spend at least $20 \%$ of their income on out-of-pocket expenses (5). An estimated 50\% of Medicare beneficiaries with cancer spend $>10 \%$ of their income on out-of-pocket expenses related to cancer treatment $(1,6)$. Treatment costs have increased over time, and patients are paying a greater portion of insurance premiums, coinsurance, and copayments (1). Some of the new, costly therapies are meant to be administered over extended periods of time (years or even indefinitely in some cases) adding to the financial impact they carry. About $28-48 \%$ of cancer survivors experience financial toxicity based upon objective measures and $16-73 \%$ experience financial toxicity based upon selfreported measures (7).

Costs associated with cancer care services (for example, co-payments, transportation, and parking) and reduced income because of loss of employment, or unplanned retirement can contribute to financial distress (8). In some instances, residual effects of the cancer or its treatment may limit patients' ability to return to their normal activities. Cancer survivors may struggle to payout-of-pocket expenses due to medical debt or loss of work $(9,10)$. This is especially true for women, younger patients, racial and ethnic minorities, low-income patients, and those without health insurance $(7,11,12)$. Cancer survivors with public insurance can experience greater financial distress than those with private insurance (13). Among low-income women, the costs of breast cancer care have been reported to be up to $98 \%$ of a patient's annual income $(14,15)$. High cancerrelated financial burden may influence choice of treatment, treatment adherence, and cancer outcomes (12). Patients who report cancer-related financial problems may be more likely to forgo medical care or prescription medications (7). Financial distress due to financial obligations, debt and diminished wealth may lead to poorer health-related quality of life and health outcomes (7).

In this commentary, we consider interventions for addressing financial toxicity in oncology practice, with the goal of identifying gaps in the current literature and suggestions for further research.

\section{Addressing financial toxicity}

Little research has been conducted on interventions for addressing financial toxicity in oncology care (16). Despite the near absence of studies on the effectiveness of interventions to reduce financial toxicity, validated tools for measuring financial toxicity and conceptual frameworks are available (4,16-18). Lentz et al. provided several recommendations for reducing financial toxicity at different levels (providers, clinic, hospital, insurance and government agencies). These authors recommended that providers ask patients about financial burden and provide patients with estimates of cancer care costs. Providers should also consider whether a clinical intervention will provide meaningful improvement (17). At the clinic level, financial toxicity screening can be incorporated into 
clinic workflow and financial navigators can be employed. Desai and Gyawali (4) proposed a four-step approach for addressing financial toxicity in cancer patients: acknowledge and understand the problem; quantify the problem; engage stakeholders and foster communication; and implement solutions at different levels of the healthcare system. At the hospital level, strong measures that hospitals can take to address financial toxicity include cost transparency and provision of financial counselors (4). An additional benefit of financial counselors is that physicians many times are not knowledgeable enough about the cost of medications and the coverage aspects of the insurance plans, may not be familiar with assistance programs, or may not have the time during a busy clinic to discuss these aspects at length with their patients.

At the level of patients and providers, increased awareness of low-value practices and financial toxicity of cancer treatment is likely to be helpful (4). Patients can obtain information about financial issues using online resources such as those provided by CancerCare.org. As noted by Zafar et al. (1): "At an individual level, patients can play a role by being active participants in decisions about their care, researching their insurance coverage, initiating discussions about the cost of care with their care team, advocating for coverage of the care that they need, and seeking financial assistance from foundations and companysponsored assistance programs." Patients may not be knowledgeable about insurance concepts such as deductibles and coinsurance (1).

Francoeur (18) identified financial interventions for cancer patients and their families: "provide education about cost-saving financial methods and decision making, improve and expand referrals to financial assistance programs and community resources, and enhance coping and adaptation strategies to manage financial stress." Clinical interventions may include increasing the financial self-efficacy of cancer patients and direct support (16). Patients can benefit from enhanced health literacy about costs (2). Evidence-based interventions such as family and group support can alleviate cancer-related distress, and help patients cope with financial toxicity (3). Problem-solving interventions may improve patients' sense of self-efficacy (3). Other interventions that may be helpful for alleviating financial toxicity include those that focus on cognitive-behavioral strategies that build patient confidence in managing cancer-related financial problems (16). Educational interventions should focus on educating patients on the basics of health insurance and costs they may face during treatment, as well as patient assistance programs (1).

Improved patient-provider communication is vital in educating cancer patients about the costs of cancer treatment (18). Some financial education resources strive to improve financial literacy and help patients to talk with their provider about the costs of oncology care (16).

\section{Discussion}

The number of cancer treatment options has increased in recent years, leading to improvements in health outcomes. These advancements are often costly (17). Not surprisingly, there has been increasing awareness of the potential for cancer care to result in financial burdens to patients $(2,11,14)$. The National Cancer Institute's Financial Toxicity and Cancer Treatment PDQ-Health Professional Version includes a conceptual framework of cancer and financial distress (19). The framework incorporates risk factors that contribute to financial distress and health outcomes; it also incorporates conditions such as out-of-pocket medical expenses, medical debt, and loss of income as well as psychological responses to financial distress. Tucker-Seeley and Yabroff (20) proposed a framework of financial wellbeing that includes the following components: "material resources to cover out-of-pocket costs, psychological responses to the financial consequences of cancer diagnosis and treatment, and behavioral strategies used to cope with the" costs of oncology care.

The number of cancer treatment options has increased in recent years, leading to improvement in patients outcomes for many malignancy types, and an overall improvement in survival after a diagnosis of cancer (17). These advancements are costly, however. Cancer is now the second most expensive disease in the United States $(17,21)$. As the cost of oncology care escalates, patient financial concerns are increasingly frequent $(22,23)$.

Health care providers can take several steps to reduce financial toxicity including: "(I) consider cost in addition to adverse effects if multiple treatment regimens have similar efficacy; (II) provide patients with estimates of cancer care costs; (III) consider whether an intervention will provide meaningful improvement; (IV) incorporate financial toxicity screening into clinic evaluation and workflow; and (V) educate and provide assistance to patients about insurance benefits, other financial aid that may be available to them, etc." (17). Referral to a financial navigator is likely to be helpful as needed (17). Financial navigators can provide financial education and counseling (17). 
A multidisciplinary approach involving nurses and social workers provides additional expertise. Social workers may help their patients locate grants from national or local community programs (3).

In conclusion, there is a great need for research to examine the effectiveness of existing interventions for addressing financial toxicity in oncology care and development of new interventions (16). This is an important gap in the current literature. Nevertheless, expert opinion indicates that oncology providers have an important role to play in addressing financial toxicity $(3,4,16,17)$. When a need is identified, early referral to a financial navigator or social worker is advisable (17).

\section{Acknowledgments}

Funding: Dr. Moore was supported by the National Institute On Minority Health And Health Disparities of the National Institutes of Health under Award Number K01MD015304.

\section{Footnote}

Provenance and Peer Review: This article was a standard submission to the journal. The article did not undergo external peer review.

Conflicts of Interest: All authors have completed the ICMJE uniform disclosure form (available at http://dx.doi. org/10.21037/jhmhp-20-68). SSC serves as an unpaid editorial board member of Fournal of Hospital Management and Health Policy from Nov 2019 to Oct 2022. The other authors have no conflicts of interest to declare.

Ethical Statement: The authors are accountable for all aspects of the work in ensuring that questions related to the accuracy or integrity of any part of the work are appropriately investigated and resolved.

Open Access Statement: This is an Open Access article distributed in accordance with the Creative Commons Attribution-NonCommercial-NoDerivs 4.0 International License (CC BY-NC-ND 4.0), which permits the noncommercial replication and distribution of the article with the strict proviso that no changes or edits are made and the original work is properly cited (including links to both the formal publication through the relevant DOI and the license). See: https://creativecommons.org/licenses/by-nc-nd/4.0/.

\section{References}

1. Zafar SY. Financial toxicity of cancer care: it's time to intervene. J Natl Cancer Inst 2015;108:djv370.

2. Zafar SY, Abernethy AP. Financial toxicity, part I: a new name for a growing problem. Oncology (Williston Park) 2013;27:80-1.

3. Chi M. The hidden cost of cancer: helping clients cope with financial toxicity. Clin Soc Work J 2019;47:249-57.

4. Desai A, Gyawali B. Financial toxicity of cancer treatment: Moving the discussion from acknowledgement of the problem to identifying solutions. EClinicalMedicine 2020;20:100269.

5. Bernard DS, Farr SL, Fang Z. National estimates of out-of-pocket health care expenditure burdens among nonelderly adults with cancer: 2001 to 2008. J Clin Oncol 2011;29:2821-6.

6. Davidoff AJ, Erten M, Shaffer T, et al. Out-of-pocket health care expenditure burden for medicare beneficiaries with cancer. Cancer 2013;119:1257-65.

7. Carrera PM, Kantarjian HM, Blinder VS. The financial burden and distress of patients with cancer: understanding and stepping-up action on the financial toxicity of cancer treatment. CA Cancer J Clin 2018;68:153-65.

8. Perry LM, Hoerger M, Seibert K, et al. Financial strain and physical and emotional quality of life in breast cancer. J Pain Symptom Manage 2019;58:454-9.

9. Dean LT, Schmitz KH, Frick KD, et al. Consumer credit as a novel marker for economic burden and health after cancer in a diverse population of breast cancer survivors in the USA. J Cancer Surviv 2018;12:306-15.

10. Pisu M, Azuero A, McNees $\mathrm{P}$, et al. The out of pocket cost of breast cancer survivors: a review. J Cancer Surviv 2010;4:202-9.

11. Jagsi R, Pottow JA, Griffith KA, et al. Long-term financial burden of breast cancer: experiences of a diverse cohort of survivors identified through population-based registries. J Clin Oncol 2014;32:1269-76.

12. Wheeler SB, Spencer JC, Pinheiro LC, et al. Financial impact of breast cancer in Black versus white women. J Clin Oncol 2018;36:1695-701.

13. Dean LT, Moss SL, Rollinson SL, et al. Patient recommendations for reducing long-lasting economic burden after breast cancer. Cancer 2019;125:1929-40.

14. Dean LT, Ransome Y, Frasso-Jaramillo L, et al. Drivers of cost differences between US breast cancer survivors with or without lymphedema. J Cancer Surviv 2019;13:804-14. 
15. Arozullah AM, Calhoun EA, Wolf M, et al. The financial burden of cancer: estimates from a study of insured women with breast cancer. J Support Oncol 2004;2:271-8.

16. Salsman JM, Bingen K, Barr RD, et al. Understanding, measuring, and addressing the financial impact of cancer on adolescents and young adults. Pediatr Blood Cancer 2019;66:e27660.

17. Lentz R, Benson AB, Kircher S. Financial toxicity in cancer care: prevalence, causes, consequences, and reduction strategies. J Surg Oncol 2019;120:85-92.

18. Francoeur RB. Reformulating financial problems and interventions to improve psychosocial and functional outcomes in cancer patients and their families. J Psychosoc Oncol 2001;19:1-20.

19. PDQ Adult Treatment Editorial Board. PDQ financial toxicity and cancer treatment. Bethesda, MD: National

doi: $10.21037 /$ jhmhp-20-68

Cite this article as: Coughlin SS, Moore JX, Cortes JE. Addressing financial toxicity in oncology care. J Hosp Manag Health Policy 2021;5:32.
Cancer Institute. Available online: https://www.cancer.gov/ about-cancer/managing-care/track-care-costs/financialtoxicity-hp-pdq

20. Tucker-Seeley RD, Yabroff KR. Minimizing the "financial toxicity" associated with cancer care: advancing the research agenda. J Natl Cancer Inst 2015;108:djv410.

21. Mariotto AB, Yabroff RK, Shao Y, et al. Projections of the cost of cancer care in the United States: 2010;2020. J Natl Cancer Inst 2011;103:117-28.

22. Stump TK, Eghan N, Egleston BL, et al. Cost concerns of patients with cancer. J Oncol Pract 2013;9:251-7.

23. Azzani M, Roslani AC, Su TT. The perceived cancerrelated financial hardship among patients and their families: a systematic review. Support Care Cancer 2015;23:889-98. 